\title{
Screening for colorectal cancer: reasons for refusal of faecal occult blood testing in a general practice in England
}

\author{
K A Hynam, A R Hart, S P Gay, A Inglis, A C B Wicks, J F Mayberry
}

\begin{abstract}
Study objective - To ascertain reasons for non-compliance with faecal occult blood tests in colorectal cancer screening programmes.

Design - A standard interview by a trained nurse of a random sample of those who declined screening.

Setting - The Leicestershire town of Market Harborough, where most of the 25000 population are served by a single general practice of 10 partners.

Participants - Altogether 4185 residents aged 51 to 70 years were invited to receive a free faecal occult blood test (Haemoccult). Eighty one subjects from a sample of 351 who wrote declining the offer were interviewed.

Main results - Non-compliers were divided into those who did not request a test kit and those who returned an unused kit. In the former group the commonest reasons given were intercurrent illness $(39 \%)$, fear of further tests and surgery $(24 \%)$, and feeling well (22\%). For those who returned unused kits the commonest reasons were the unpleasantness of the stool collection procedure $(65 \%)$, feeling well $(30 \%)$, intercurrent illness $(23 \%)$, and fear of further tests and surgery $(20 \%)$. In both groups the main concern of those who did not comply were fear of further diagnostic tests and surgery rather than concern at the lack of effective treatment for cancer.

Conclusions - To increase compliance, education and publicity must explain the concept of asymptomatic illness and allay people's fear of hospital investigation and treatment. The benefits of screening should be particularly emphasised to those who return kits so they may overcome their reservations.
\end{abstract}

(f Epidemiol Community Health 1995;49:84-86)

Colorectal cancer is the second commonest cause of death from malignancy in Britain, and results in over 20000 fatalities each year. Results of large screening trials in which faecal occult blood tests are administered to asymptomatic people show that cancers thus detected are less advanced than those in patients who present with symptoms. ${ }^{2-6}$ Colonoscopy of those with positive tests identifies adenomas and their removal may prevent progression to malignancy. ${ }^{7-9}$ The Minnesota colon cancer control study ${ }^{10}$ has recently reported a $33 \%$ reduction in mortality at 13 years through the use of annual faecal occult blood testing and colonoscopy.

For screening to be effective in both health and economic terms compliance must approach $70 \% .{ }^{11}$ In faecal occult blood testing programmes in general practice compliance can reach $50 \%,{ }^{2}$ but it is often lower ${ }^{12-16}$ and the reasons subjects decline the test are poorly understood.

This study aimed to assess the reasons for non-compliance in those who rejected an offer of screening by their general practitioner in the town of Market Harborough. This community has a population of 23000 with most people working in local industry or the surrounding countryside. It is hoped that more acceptable screening programmes can be developed if the reasons for refusal can be addressed.

\section{Method}

Colorectal cancer screening was offered to residents of Market Harborough aged 51 to 70 years. ${ }^{12}$ Over 4000 people who were registered with a single general practice of 10 doctors were eligible to participate. The scheme was publicised in the local newspaper and on radio. Residents received a letter from their general practitioner which explained screening and offered a free faecal occult blood test (Haemoccult). Tests were analysed at the Leicester General Hospital and those with positive results were colonoscoped in the hospital's endoscopy unit. A random sample from a group of 351 people who replied declining the test or returned an unused kit was interviewed to ascertain reasons for rejection. Non-compliers were contacted by phone and a convenient time for interview was arranged by a single research nurse. Those who were unwilling to be seen at home were asked if they would answer a structured questionnaire by telephone. Residents were told that the purpose of the study was to understand reasons for non-compliance so that more effective screening programmes could be designed. An assurance was given that answers were strictly confidential.

A structured questionnaire (see appendix 1) which contained 11 reasons for rejection was used as the basis for the interview. The questionnaire was compiled by a discussion group comprising two hospital doctors, a general practitioner, a research nurse, and two nonmedical lay people. No standard questionnaire exists for inteviewing those who decline faecal 
Reasons for non-compliance with the faecal occult blood test

\begin{tabular}{|c|c|c|}
\hline $\begin{array}{l}\text { Reason for } \\
\text { non-compliance }\end{array}$ & $\begin{array}{l}\text { Kit not } \\
\text { requested } \\
(n=41) \\
\text { No }(\%)\end{array}$ & $\begin{array}{l}\text { Uncompleted } \\
\text { kit returned } \\
(n=40) \\
\text { No }(\%)\end{array}$ \\
\hline $\begin{array}{l}\text { Intercurrent illness } \\
\text { Afraid of further tests and } \\
\text { srugery }\end{array}$ & $\begin{array}{l}16(39) \\
10(24)\end{array}$ & $\begin{array}{l}9(23) \\
8(20)\end{array}$ \\
\hline $\begin{array}{l}\text { Felt well } \\
\text { Stool collection unpleasant } \\
\text { No treatment } \\
\text { Bowel cancer rare } \\
\text { No family history }\end{array}$ & $\begin{array}{ll}9 & (22) \\
4 & (10) \\
1 & (2 \cdot 5) \\
0 & (0) \\
0 & (0)\end{array}$ & $\begin{array}{cc}12 & (30) \\
26 & (65) \\
1 & (3) \\
1 & (3) \\
1 & (3)\end{array}$ \\
\hline
\end{tabular}

More non-compliers who returned an unused kit thought "stool collection unpleasant" than non-compliers who did not request kits $\left(65 \% v 10 \%, \chi^{2}=26.5, p<0.0001\right)$.

occult blood tests so validation with other work was not possible. Answers were recorded as "yes" or "no". People were asked to indicate one or more reasons which best described why they declined.

Non-compliers were divided into two groups - those who wrote back declining a kit and those who returned an unused kit. The frequency of stated reasons were analysed between the two groups of non-compliers using a $\chi^{2}$ statistic. People who wanted to participate after the interview were sent a Haemoccult kit from the hospital.

\section{Results}

In Market Harborough, 2611 people from a sample of 4000 did not take up the offer of screening. ${ }^{12}$ From this group, 351 people actually wrote back declining screening or returning unused kits. Approximately two thirds of the group were women. One hundred subjects from this group were contacted and 81 ( 58 women, $23 \mathrm{men}$ ) were prepared to give their reasons for non-compliance. Of these, 54 interviews were conducted at home and the remaining 27 by telephone. Of those interviewed, 41 had not requested a kit and 40 requested a test but failed to return it.

The commonest reasons for non-compliance given by the 81 subjects were: stool collection unpleasant ( $37 \%$ subjects), intercurrent illness ( $31 \%$ subjects), felt well ( $26 \%$ subjects), and frightened by the prospects of more tests and surgery (22\%) (table). Only three subjects (4\%) did not participate because of "lack of known treatment", "no family history of bowel cancer", or "bowel cancer is so rare I am unlikely to have it". No one failed to comply because of religious beliefs or because they had been advised not to by another individual. All but one of those interviewed understood that the test was to detect colorectal cancer. Everyone realised kits were free and the cost of postage was covered.

The reasons classified according to the two sub-groups of non-compliers are shown in the table. In both sub-goups subjects were more concerned about further tests and surgery than they were at the lack of effective treatment. The only significant difference between the two subgroups was that more non-compliers who requested and returned an unused kit thought "stool collection was unpleasant" than non- compliers who did not even request a test $(65 \%$ $v 10 \%$ subjects, $\left.\chi^{2}=26 \cdot 5, \mathrm{p}<0 \cdot 0001\right)$. There were no other significant differences between the two subgroups in the number of non-compliers $\left(\chi^{2}<2 \cdot 6, N S\right)$.

\section{Discussion}

The purpose of a non-compliance study is to identify potentially reversible reasons. In Market Harborough, a quarter of people did not participate because they felt well and did not therefore see any need to be screened. Similarly, in an occupational colorectal cancer screening service over half the employees did not respond as they had no bowel symptoms. ${ }^{17}$ In a community survey, Farrands et $a l^{18}$ found that only $43 \%$ of non-compliers believed in the concept of asymptomatic illness and only $62 \%$ felt medical tests could show such disease. Clearly if screening is to succeed educational programmes are needed to explain its concepts and benefits. Some participants find kits unpleasant, difficult to collect, time consuming, ${ }^{17}$ and embarrassing. ${ }^{19}$ In a community based study in Oxfordshire five times as many nonparticipants as participants reported the collection procedure as disgusting. ${ }^{20}$ Such views revolve around the concept of "dignity" and if tests cannot be more dignified, emphasising the benefits of screening may be the only way of overcoming this reluctance to participate. Other tests such as Coloscreen, which uses toilet paper impregnated with the screening reagent, are more acceptable to patients, although the efficacy has not been analysed in a large trial. ${ }^{20}$

A quarter of people were afraid of further tests after a positive result. This fear was more influential than concern about a lack of effective treatment for colorectal cancer. In an American programme non-compliers were significantly more likely to object to sigmoidoscopy, barium enema, and colonoscopy than volunteers. Unfortunately the public perceive such investigations as lacking in dignity, unpleasant, and painful.

Over $25 \%$ of people interviewed gave intercurrent illness as a barrier to their participation. A third of these illnesses were either reversible or not a contraindication to screening. In a Danish study 22 34 declined because of coexistent disease or current medical treatment. An explanation that people may enroll after resolution of intercurrent illness with later follow up in the screening programme may increase their uptake.

In all non-compliance studies, some people refuse to be interviewed and so reasons given by those who cooperate may not be representative of the whole group. In our study, consent for interview was high, $81 \%$ of people we contacted cooperated. In Leicestershire we specifically targeted those who wrote back and declined screening or returned the kit. Over a quarter of this sample was approached to be interviewed, although the total number questioned is relatively small. However, much time was spent contacting a hundred subjects by telephone and conducting the interviews in the 
privacy of their homes at a time that suited them. Often non-compliers claim that they do not have time or can't "be bothered" to participate. ${ }^{17,18,22}$ These are unlikely to be the real reasons and probably mask fears about cancer. In Market Harborough, the commonest reasons, namely the unpleasantness of the test procedure and intercurrent illness may be "excuses" in people fearful of dying from cancer. Many more may be worried about further hospital tests but are reluctant to admit this concern to the interviewer. The number who declined testing kits because they "felt well" is probably accurate. Subjects would not give this response if they understood screening and asymptomatic illness for fear of looking ignorant. The health belief model, ${ }^{23}$ which investigates health behaviours, assesses motivation, disease susceptibility and severity, benefits, cues and barriers to participating. Cues include publicity about screening and knowing someone with colorectal cancer. Macrae et al ${ }^{19}$ applied this model to colorectal cancer screening and found refusers thought they were less susceptible, although their perception of the disease's severity was identical to acceptors. Refusers were less motivated about health and disliked occult blood tests. Public awareness about the high incidence of colorectal cancer may persuade these people to participate.

To be effective screening programmes must have a high compliance rate. This is yet to be achieved in surveys offered to all members of the public. More people may participate if there is adequate publicity and education about the frequency of colon cancer and the potential benefits of early detection. In addition, the concept of asymptomatic illness must be promoted and fears allayed about diagnostic tests.

\section{Appendix 1}

The following questionnaire was completed with the assistance of a research nurse by telephone or in the patient's home.

\section{MARKET HARBOROUGH NON-COMPLIANCE STUDY QUESTIONNAIRE.}

We would be interested to know why you chose not to receive a test kit so that in the future we may plan better tests. Please could you tell us which of the following reasons made you decide not to receive a test kit.

(1) There was no stamped addressed envelope in which to return my reply.

(2) The thought of collecting the motions repelled me.

(3) I have another illness and do not wish to undergo further tests.

(4) Did you realise the test was to diagnose bowel cancer?

(5) I would be afraid of having bowel cancer diagnosed as I thought that there was no known treatment.
(6) I would be frightened by the thought of more tests and a possible operation.

(7) There is no history of bowel cancer in my family so I do not need a test.

(8) I was told by another person not to complete the test.

(9) I did not complete the test as bowel cancer is so rare that I am unlikely to have it.

(10) Religious beliefs prevented me completing the test.

(11) I did not realise the test was free.

(12) Other reason.

1 Office of Population Censuses and Surveys. Mortality stat istics 1990. London: HM Stationery Office, 1991. Serie DH 2,17 .

2 Hardcastle JD, Chamberlain J, Sheffield J, et al. Randomised control trial of faecal occult blood screening for colorectal cancer. Lancet 1989; i: 1160-4.

3 Thomas WM, Hardcastle JD. An update on the Nottingham trial of faecal occult blood screening for colorectal carcinoma. In: Miller AB, Chamberlain J, Day N, eds. Cancer screening. Cambridge: Cambridge University Press, 1991, 106-15.

4 Kronborg O, Fenger C, Sondergaard O, Pedersen KM Olsen J. Initial mass screening for colorectal cancer with Olsen J. Initial mass screening for colorectal cancer with faecal occult blood. Scand f Gastroenterol 1987;22:677-86. Winnawer SJ, Andrews M, Flehinger B, Sherlock P,
Schottenfeld D, Miller DP. Progress report on control Schottenfeld D, Miller DP. Progress report on control trial of faecal occult blood testing for the detal neoplasia. Cancer 1980;45:2959-64.

6 Kewenter J, Asztely M, Engaras B, et al. A randomised trial of faecal occult blood testing for early detection of colorectal cancer. Results of screening and rescreening of 51325 subjects. In: Miller AB, Chamberlain J, Day B, eds. Cancer screening. Cambridge: Cambridge University Press, 1991;116-25.

7 Stryker SI, Wolff BG, Culp CE, Libbe SD, Ilstrup DM MacCarty RL. Natural history of untreated colonic polyps. Gastroenterology 1987;93:1009-13.

8 Muto T, Bussey JR, Morson BC. The evolution of cance of the colon and rectum. Cancer 1975;36:2251-70.

9 Jackman RJ, Mayo CW. The adenoma-carcinoma sequence in cancer of the colon. Surg Gynecol Obstet 1951;267: 469-75.

10 Mandel JS, Bond JH, Church TR, Snover DC, Bradley GM, Schuman LM, Ederer F. Reducing mortality from colorectal cancer by screening for fecal occult blood. $N$ Engl f Med 1993;328:1365-71.

11 Atkin WS, Cuzick J, Northover JMA, Whynes DK. Prevention of colorectal cancer by once-only sigmoidoscopy. Lancet 1993;341:736-40.

12 Hart AR, Gay SP, Donnelly A, Griffin L, Inglis A, Mayberry MK, Wicks ACB, Mayberry JF. Screening for colorecta cancer. A community based programme in general practice. European fournal of Gastroenterology and Hepatology 1994;6:519-22

13 Farrands PA, Griffiths RL, Britton DC. The Frome experiment-value for screening for colorectal cancer. Lance 1981;i:1231-2.

14 Million R, Howarth J, Turnberg E, Turnberg LA. Faecal occult blood testing for colorectal cancer in general practice. The Practitioner 1982;226:659-63.

15 Lallemand RC, Vakil PA, Pearson P, Box V. Screening for asymptomatic bowel cancer in general practice. $B M$ 1984;288:31-3.

16 Hobbs FDR, Cherry RC, Fielding JWL, Pike L, Holder R Acceptability of opportunistic screening for occult blood Acceptability of opportunistic

17 Silman A, Mitchell P. Attitudes of non-participants in an occupational based programme of screening for colorectal occupational based programme of screening

18 Farrands PA, Hardcastle J, Chamberlain J, Moss S. Factors affecting compliance with screening for colorectal cancer. affecting compliance with screening

19 Macrae FA, Hill DJ, St John JB, Ambikapathy A, Garne JF. Predicting colon cancer screening behaviour from health beliefs. Prev Med 1984;13:115-126.

20 Hunter W, Farmer A, Mant D, Verne J, Northover J, Fitzpatrick R. The effect of self-administered faecal occult blood tests on compliance with screening for colorectal cancer: Results of a survey of those invited. Family Practice 1991;8:367-72.

21 Spector MH, Applegate WB, Olmstead SJ, DiVasto P, Skipper B. Assessment of attitudes toward mass screening for colorectal cancer and polyps. Prev Med 1981;10:105-9.

22 Klaaborg K, Stahl Madsen M, Sondergaard K, Kronborg O. Participation in mass screening for colorectal cance with faecal occult blood test. Scand f Gastroenterol 1983; 21:1180-4.

23 Becker $M$ (ed). The health belief model and personal behaviour. Health Education Monographs 1974;2:324-474. 